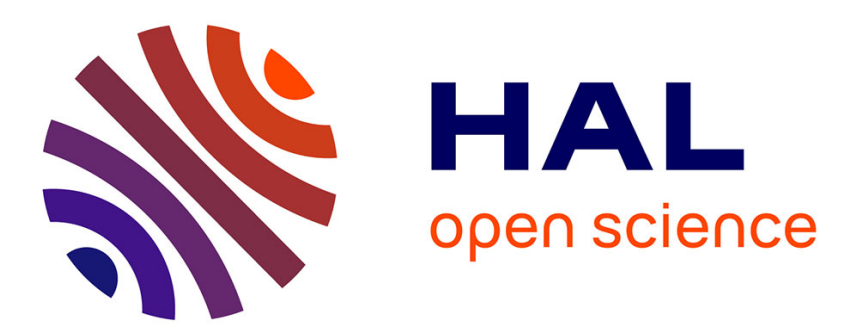

\title{
Prediction of Transient Engine Loads and Damage due to Hollow Fan Blade-off
}

Nicolas Cosme, David Chevrolet, Jérome Bonini, Bernard Peseux, Patrice Cartraud

\section{- To cite this version:}

Nicolas Cosme, David Chevrolet, Jérome Bonini, Bernard Peseux, Patrice Cartraud. Prediction of Transient Engine Loads and Damage due to Hollow Fan Blade-off. Revue Européenne des Éléments Finis, 2002, 11 (5), pp.651-666. 10.3166/reef.11.651-666 . hal-01007197

\section{HAL Id: hal-01007197 https://hal.science/hal-01007197}

Submitted on 5 Oct 2016

HAL is a multi-disciplinary open access archive for the deposit and dissemination of scientific research documents, whether they are published or not. The documents may come from teaching and research institutions in France or abroad, or from public or private research centers.
L'archive ouverte pluridisciplinaire HAL, est destinée au dépôt et à la diffusion de documents scientifiques de niveau recherche, publiés ou non, émanant des établissements d'enseignement et de recherche français ou étrangers, des laboratoires publics ou privés.

\section{(c)(1)}

Distributed under a Creative Commons Attribution| 4.0 International License 


\title{
Prediction of transient engine loads and damage due to hollow fan blade-off
}

\author{
Nicolas Cosme*,** — David Chevrolet* — Jérôme Bonini* \\ Bernard Peseux** — Patrice Cartraud**
}

* Snecma Moteurs, site de Villaroche

F-77550 Moissy Cramayel

\{nicolas.cosme, david.chevrolet, jerome.bonini\}@snecma.fr

** Laboratoire Mécanique et Matériaux, Ecole Centrale de Nantes

1 rue de la Noё, BP 92101, F-44321 Nantes cedex 3

\{bernard.peseux, patrice.cartraud\}@ec-nantes.fr

ABSTRACT. The loss of a fan blade causes serious damages on an engine and can endanger the
aircraft integrity and the safety of passengers. Commercial aircraft engines must then meet
the FAA (Federal Aviation Administration) and JAA (Joint Aviation Authorities) certification
requirements concerning the fan blade containment. The certification is validated through a
Fan Blade-Off (FBO) test on a whole engine. The success in this test requires destructive and
expensive development tests performed at the different stages of the design process. To
reduce the number of these experiments and thus, the costs and the time of development, the
engine behaviour under FBO can be understood and even predicted thanks to finite element
(FE) analysis. This paper shows a comparison between a FBO simulation of hollow blades,
computed with an explicit integration FE code, and experimental data obtained during an
intermediate FBO test carried out by Snecma Moteurs. The results of the load levels and the
similarity on the sequence of events show good agreement. RÉSUMÉ. La perte d'une aube fan peut causer de graves dommages dans un moteur, et mettre en danger l'intégrité de l'avion et la sécurité des passagers. Les moteurs d'avion civil doivent donc répondre aux exigences de certification de la FAA et de la JAA sur la perte d'aube. La certification est validée par un essai de perte d'aube sur moteur complet. La réussite de cet essai nécessite la réalisation d'essais partiels destructifs, coûteux et qui ne peuvent être réalisés qu'à la fin du cycle de conception. Pour réduire le nombre d'essais et donc les coûts et délais de développement, la simulation par éléments finis peut permettre de comprendre et même de prédire le comportement du moteur en perte d'aube. Cet article présente la comparaison entre la simulation d'une perte d'aube creuse, effectuée à l'aide d'un code explicite, et des données expérimentales mesurées lors d'un essai intermédiaire effectué par Snecma Moteurs. Les résultats sur les niveaux de charges et la similarité de la séquence d'événements montrent une bonne corrélation.

KEYWORDS: Fan blade-off, non-linear transient dynamics, explicit computation, impact.

MOTS-CLÉs : Perte d'aube fan, dynamique transitoire non-linéaire, calcul explicite, impact. 


\section{Introduction}

The release of a blade remains one of the most critical failures that can occur in a turbofan engine after a manufacturing defect or in-flight damage. The induced out of balance force and the high-energy impacts of the blade fragments cause very high loading in the whole structure that can lead to further deterioration in the engine components and even aircraft damage. That is why the airworthiness authorities impose severe criteria to ensure that the engine contains the fragments and runs down safely without any risk for the aircraft. To allow a new civil engine to entry into commercial service, manufacturers must demonstrate its capability to satisfy the criteria with a successful FBO certification test performed on a full engine. These requirements must consequently be considered in the design of each component. Manufacturers carry out numerous development spin tests to validate their initial technological and mechanical choices. However these experiments are very expensive and any failure should considerably delay the whole qualification process and increase the global cost of the project. Moreover, as fan diameters are getting larger to improve performances, problems of weight optimisation and of impact resistance to heavy high-speed fragments are becoming crucial.

Simplified approaches such as energy balance method or multi-body analysis can allow to evaluate the failure risks for some components in the preliminary design. But, they do not take into consideration many factors, such as nonlinearities, dynamic effects or component interactions, which have been proved to have an important role in the overall engine response. FE analysis seems then to be essential for a manufacturer like Snecma Moteurs to better understand the FBO event and predict the engine behaviour with good accuracy. This type of analysis allows a confident design and optimisations indeed, and the number of intermediate tests can be reduced. Furthermore, the numerical simulation can be used to design and validate the developments and modifications on a certified engine without carrying out new certification FBO tests. Until now, implicit computations are used to simulate the transient and harmonic behaviour of a complete engine after a FBO event with a simplified model. In particular, the model does not take into account the dynamic effects of the released blade, and the material laws are generally linear. On the other hand, explicit codes are efficient to study the transient loads and damage due to a FBO. As explicit computations require a refined FE mesh of the engine geometry, the models include in general the front part of the engine only. Now the main task lies in simulating the transient behaviour during a FBO downstream the fan stage. It consists thus in determining a suitable industrial calculation procedure, including the FE model specificity and hypothesis to obtain good correlation with tests.

The objectives of this study is to present an application of a FBO simulation on a hollow fan blade engine. The experiments conducted during the design process provide valuable data to demonstrate the interest and robustness of the computation. 


\section{Description of the Fan Blade-Off event}

The first stage of the study is to describe the FBO event in order to identify and understand the major phenomena that occur. The following list is a generic sequence of events or characteristic behaviours observed by high speed cameras in a typical FBO experiment:

- release of the blade: in a test, it is initiated with an explosive located at the blade root;

- first impact of the released blade tip on the fan casing;

- orbit of the rotor: the loss of a blade from a fan rotating at high speed creates a considerable out of balance force. The rotor tends then to orbit so as to rotate around its new centre of gravity;

- fragmentation of the released blade: after the tip of the released blade hits the casing, the blade rolls up along the casing and starts to break into fragments;

- deformations of the fan casing: the role of the fan casing is to guide the airflow but also to preserve the integrity of the engine and aircraft. In case of a FBO event, it must thus contain the fragments and endure the structural loads without dangerous rupture risks;

- impact of the released blade root on the trailing blade pressure face, as the rotor keeps on rotating and the blade moves out in radius towards the casing;

- behaviour of the following blades: following the orbiting of the rotor and the different impacts, the blades remaining on the disc vibrate and may rub against the distorted casing;

- dynamic load transmission in the structure: the energy transmitted from the rotor to the stator (through the impacts, the bearings...) generates high loads, which spread inside the rest of the structure. It can cause the opening of the bolted flanges and the failure of the fuse if such a system is used.

\section{Test description}

During the design process, manufacturers perform several tests at different steps of the process to validate the component conception. As an engine certification requirement, the fan blade retention involves then a special attention in the design and requires specific tests. To enhance the thrust of the engine and therefore its performances, one solution consists in increasing the fan diameter. Nevertheless with this solution, the engine tends to get heavier and the loads carried by the structure become considerable. To reduce the addition of weight and load in the test engine, the fan blades are not classical solid blades but wide chord (distance from the leading to the trailing edge) titanium hollow blades with stiffeners inside. The outer skin shapes define the airflow and the stiffeners ensure the mechanical strength. 
The engine studied in this work must enable to validate a number of components subjected to FBO load conditions. It is then simply composed of the front part of the engine, as shown in figure 1. Moreover, only several undamaged and one truncated blades are assembled on the disc. The rotor is counterbalanced with masses, calibrated and placed all around the disc instead of real blades. To reduce the loads due to the FBO event in the rest of the engine (and in particular in the structural casing), the engine comprises a fuse, sized up to snap at a determined load.

With this engine configuration, the FBO test is conducted under vacuum: the rotor is speeded up progressively to its nominal rotation speed thanks to a driving motor. Then the loss of the blade is activated by an explosive located at the root of the released blade. The engine is instrumented with accelerometers and strain gauges to measure the structural engine response.

\section{Model features}

Once the FBO event is well understood and the engine geometry is defined, decisions can be made to select the suitable strategy and FE model used for the numerical simulation.

\subsection{Choice of the integration scheme}

The issue is to predict with good accuracy the transient behaviour of the structure under impact in the few milliseconds following the blade-off event. The calculations should preferably be performed with an explicit dynamic code (Belytschko et al, 1983) (Hughes, 1987).

The non-linear transient analysis code, chosen by Snecma Moteurs to perform this FBO simulation is PLEXUS (Lepareux et al, 1997), developed at the French Commissariat à l'Energie Atomique (CEA). The explicit method for the resolution algorithm is based on the classical Newmark central difference integration (Newmark, 1959). For this type of simulation with large displacements and deformations, the code employs the updated lagrangian formulation: the configuration of reference is redefined at each time step. The equations for the discrete nodal displacements and velocities can be written:

$$
\left\{\begin{array}{l}
\mathrm{x}^{\mathrm{n}+1}=\mathrm{x}^{\mathrm{n}}+\Delta \mathrm{t} \quad \dot{\mathrm{x}}^{\mathrm{n}}+\frac{(\Delta \mathrm{t})^{2}}{2} \\
\ddot{\mathrm{x}}^{\mathrm{n}+1}=\dot{\mathrm{x}}^{\mathrm{n}}+\frac{\Delta \mathrm{t}}{2}\left(\ddot{\mathrm{x}}^{\mathrm{n}}+\ddot{\mathrm{x}}^{\mathrm{n}+1}\right)
\end{array}\right.
$$


where $\mathrm{n}$ and $\mathrm{n}+1$ are the time step indexes,

$\Delta \mathrm{t}$ is the time step size,

$\mathrm{x}^{\mathrm{i}}, \dot{\mathrm{x}}^{\mathrm{i}}, \ddot{\mathrm{x}}^{\mathrm{i}}$ are the nodal displacement, velocity and acceleration vectors at time step i.

The dynamic equation of motion becomes then:

$$
\mathrm{M} \ddot{x}^{\mathrm{n}+1}=\mathrm{F}_{\mathrm{ext}}^{\mathrm{n}+1}-\mathrm{F}_{\mathrm{int}}^{\mathrm{n}+1}
$$

where $\quad \mathrm{M}$ is the diagonal mass matrix.

$\mathrm{F}_{\text {int }}$ and $\mathrm{F}_{\text {ext }}$ are the internal and external nodal force vectors.

The explicit algorithm is very efficient in terms of calculation time when the resolution does not require matrix inversions at each time step. Therefore the mass matrix is lumped. The choice of the lumping method is adapted to the element type.

The central difference method is conditionally stable, and the stability limit for the system without damping is given by the Courant condition:

$$
\Delta \mathrm{t} \leq \operatorname{Min}_{\mathrm{e}}\left(\frac{\mathrm{L}_{\mathrm{e}}}{\mathrm{C}_{\mathrm{e}}}\right)=\Delta \mathrm{t}_{\text {stab }}
$$

with $\Delta \mathrm{t}_{\text {stab }}$ is the critical stable time step size,

$\Delta \mathrm{t}$ is the time step size used in the calculation with a safety factor,

$\mathrm{L}_{\mathrm{e}}$ is the smallest dimension of the element $\mathrm{e}$,

$\mathrm{Ce}=\sqrt{\mathrm{E} / \rho}$ is the sound speed in the element e.

As the FBO event involves extreme loadings, the mesh tends to get highly distorted. The time step size must thus be calculated at each time step to ensure the Courant condition and to allow the computation to proceed.

\subsection{FE model}

The description of the FBO event presented previously shows that phenomena, such as the blade fragmentation, can be very local, and that the global behaviour of the engine depends on the different component interactions: blades with blades, blades with casing, rotor with bearings... Besides, with the significant progress in computational structural dynamics and in hardware and parallel processing technologies, the industrial FE model can be composed of numerous degrees of freedom (DOF). As a consequence, in order to describe precisely the structure 
behaviour, it is important to model each component geometry in detail, as far as possible.

The complete model includes all the components of the engine mounted on the test stand, i.e.:

- several wide chord hollow fan blades assembled on the disc, and one truncated hollow blade, preceding the released blade. The blades are separated by platforms, whose role in flight conditions is to ensure the shape of the entering airflow at the blade root,

- the fan disc with the masses,

- the low pressure shaft and two fan modulus bearings,

- the containment casing and a simplified intermediate structural casing,

- a simplified booster and its casing to represent the rotor/stator contact in the booster, and consequently the load transmission to the stator,

- a fuse system, to minimise the loads on the engine and aircraft structures after a FBO,

- other pieces belonging to the test stand or to the engine-to-stand attachment.

The geometry of the FE model is presented below in figure 1 .

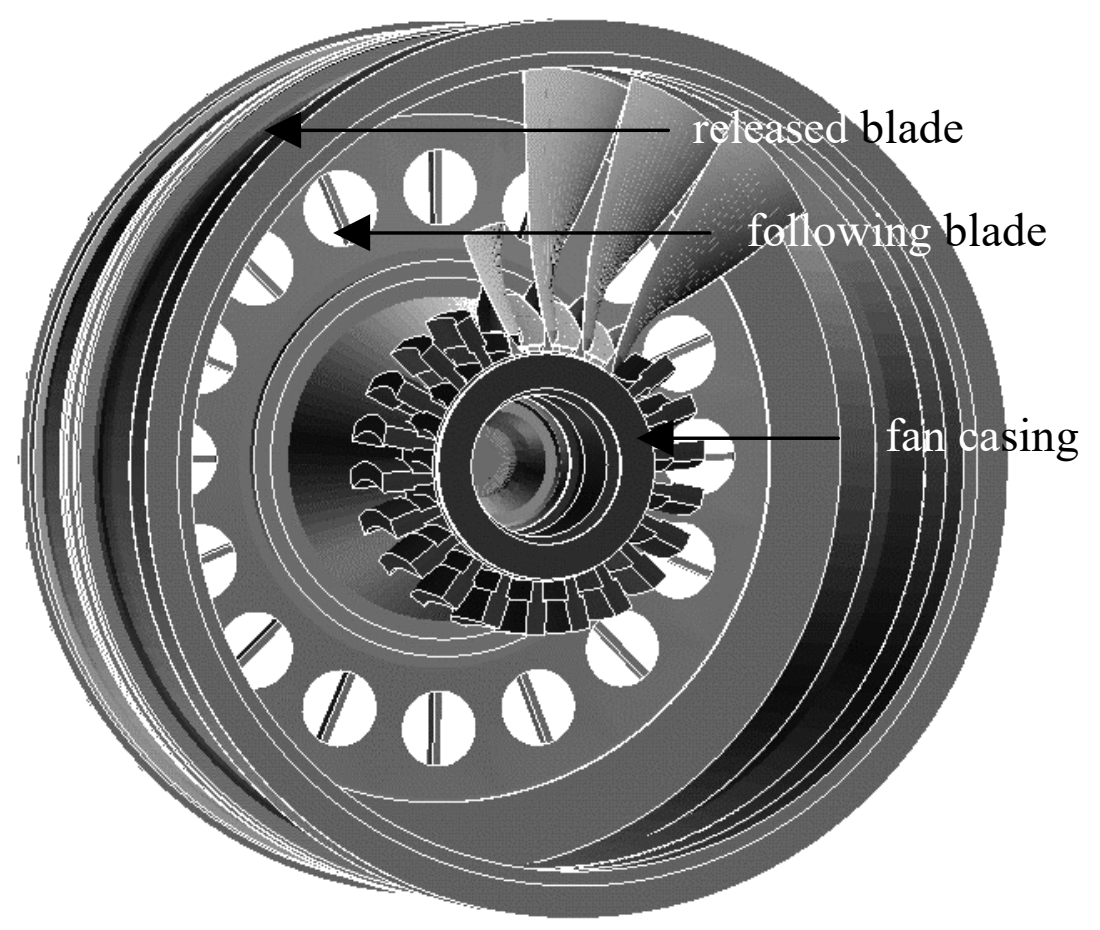

Figure 1. FE model geometry of the test engine 
This model is meshed with 3D linear elements (shell, shell brick and brick elements) and includes approximately 500,000 DOF.

However, some components could not be represented completely in such a calculation, and require simplified specific model. The simplifications consist essentially in using linear behaviours instead of complex non-linear models.

\subsubsection{Bearing and bolted flange models}

The bearing model used in this simulation is linear. Zero bearing to housing clearance is assumed and the ball inertia effects are neglected. The stiffness of the bearing has been calculated by static measurements under unidirectional loading.

Numerous components of an aircraft engine are linked with bolted flanges. But a complex model including the meshing of all the bolts with many contacts is too expensive in terms of calculation time. That is why the simulation uses a simple model where the bolts are not meshed and, material and contact non-linearities are not taken into consideration.

\subsubsection{Boundary conditions and engine-to-stand attachment}

The only connections between the development engine and the test rig are composed of an elastomer ring joint for the stator and a driving shaft for the rotor. The links are supposed linear; thus the local non-linear phenomena are ignored. In particular, the joint circumference is supposed to be perfectly embedded and the axial displacement of the shaft end is blocked. Moreover, for this study, the material behaviour of the elastomer, identified as a visco-elastic law, is considered linear, because the damping has little influence on the response during the first engine round.

\subsubsection{Material laws}

The constitutive materials of the whole structure are described with linear elastic laws, excepted for the blades and the fan casing. For these components, the material behaviours are described with appropriate dynamic elastic-plastic laws, with a dependence on the strain rate. The coefficients of the strain-stress relations have been identified with Split-Hopkinson Bar (Noble et al, 1999) tests in a very wide range of deformation speed: the impact rates of strain are of the order of $1000 \mathrm{~s}^{-1}$.

\subsection{Contact definition}

Numerous contacts are considered between the different components, in particular between the released blade and the fan casing, between the released blade and the other blades, and between the shaft and the booster casing. 
The contact detection consists in a slave nodes-master surfaces technique. At this stage, several solutions are available to compute the nodal contact forces. The first one is the penalty method, described in (Hallquist et al, 1985). The second one uses the Lagrange multiplier method applied to an explicit code, and described in (Bonini et al, 1997). Velocity constraints are chosen for the minimisation technique that ensure the continuity of contact conditions between the structures, without using a shock stiffness coefficient provided by the user. The last technique has been chosen for the application. Moreover, on the sliding surface, friction can be introduced according to the Coulomb law.

\section{Calculation procedure}

Two successive steps are required to perform the FBO simulation:

- the first operation consists in counterbalancing the rotor. In the presence of both blades and masses, the cyclic symmetry of the rotor is not respected: the FE discretisation involves an additional unbalance, which is cancelled by modifying the density of several masses. The dynamic behaviour of the rotor is greatly influenced by the strength of the centrifugal stresses. The centrifugal forces are determined in the rotating frame with Plexus. They are applied on each node of the rotor and are damped on the first bending mode of the blade.

- the complete FBO simulation is performed at the nominal rotation speed in a fixed frame. The pre-stresses calculated at the first step are injected as initial state of the rotor. The initial velocity field is introduced automatically by the code at each node of the rotor from the radial position and rotation speed. Since the test is carried out in vacuum, no aerodynamic loads are applied.

\section{Analysis and results}

\subsection{Pre-stresses}

The result of the pre-stresses field in the rotor is shown in figure 2. The range of stress values can be compared to the results obtained with implicit time integration simulation. The stress field repartition and the relative symmetry on the disk confirm that the structure is fairly well balanced. The difference of the stress values over the disc circumference is limited and is coherent with the balance of an engine mounted on a test rig. 


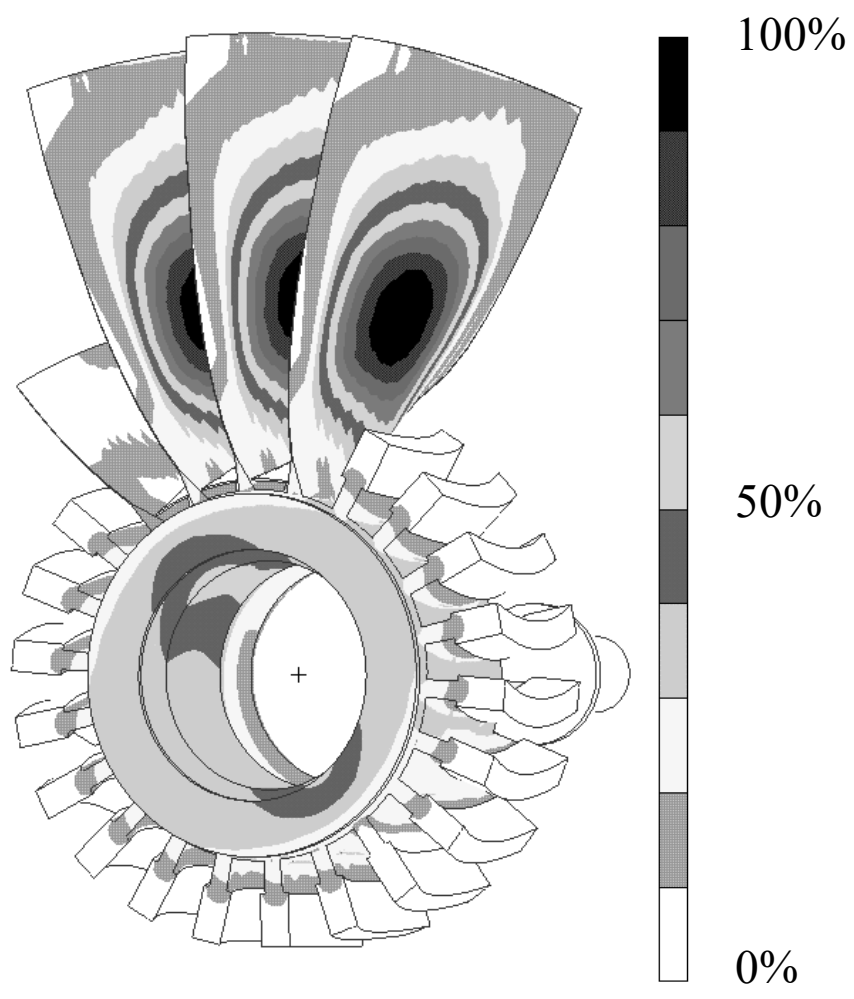

Figure 2. Von Mises pre-stresses field in the rotor

\subsection{FBO simulation}

The main objective of this paper is to prove that the technique enables to predict the loads in the engine with good agreement. That is why the results of the computation are compared to experimental data obtained during the related FBO test.

The simulation has been performed until a physical time corresponding to one engine round, when the major non-linear phenomena described occur.

\subsubsection{Fragmentation of the released blade}

The fragmentation process of the released blade when it hits the containment casing influences its kinematic, and thus, the impact position on the following blade. Therefore, a good representation of this fragmentation sequence is required to reproduce properly the contact between the two blades and the whole FBO event.

In order to evaluate the damage and define the fragments of the blade, a criterion depending on the equivalent plastic strain is used. Since the fragments are not computed automatically in the present application, iterations are necessary to calculate the instants and positions of the fragments occurring successively. When the fragments are completely defined, they can be introduced as a programmed condition in order to proceed the complete FBO simulation from the beginning. 
The first stage consists in validating the range of values for the strain rate, when the released blade impacts the fan casing. Figure 3 shows that the calculated strain rates stay in the experimental range.

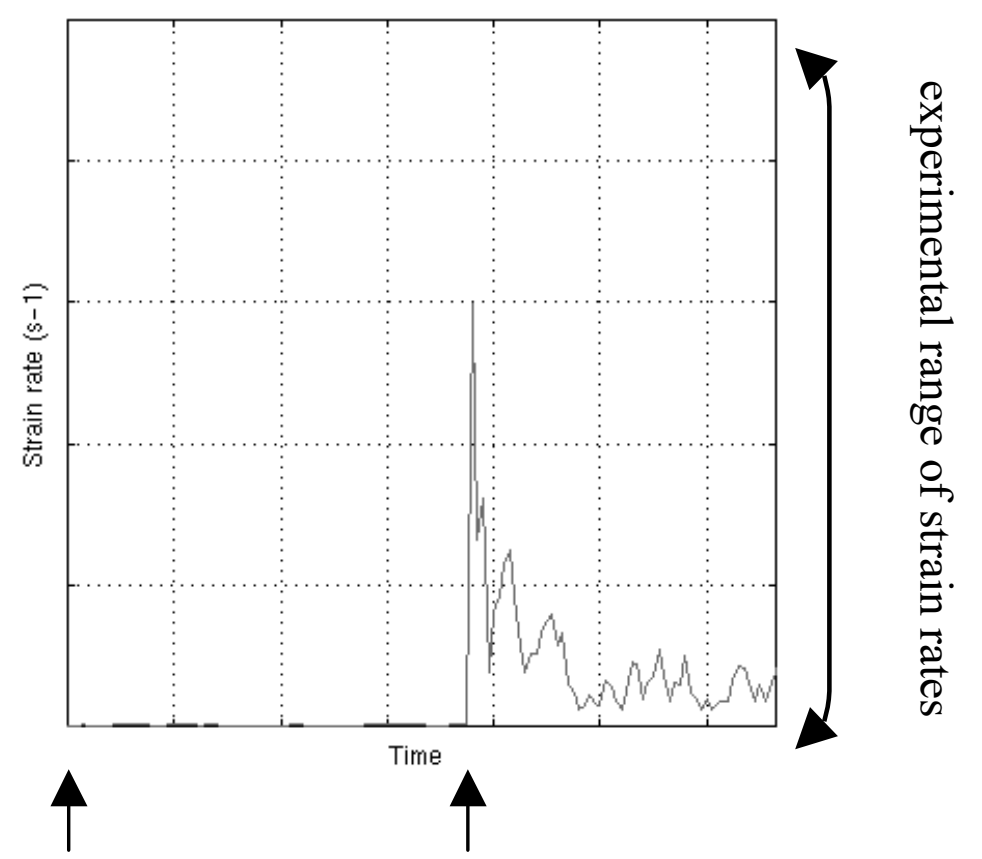

blade release impact of the released blade against the casing

Figure 3. Strain rate in the impact area of the released blade versus time

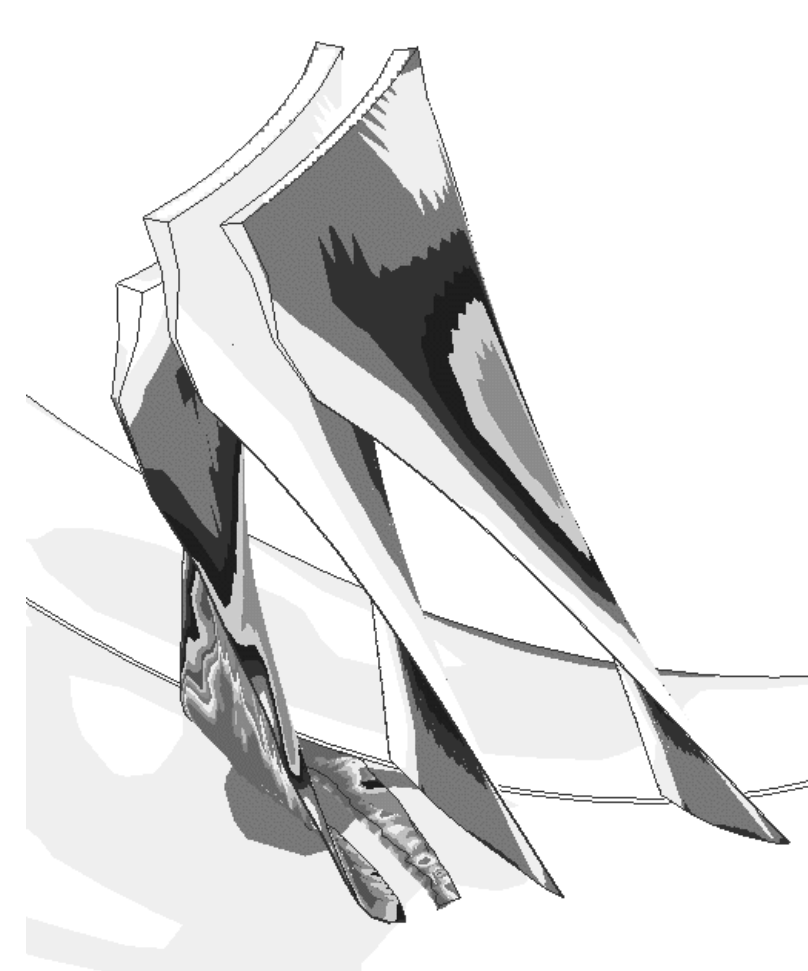

(a) First fragment

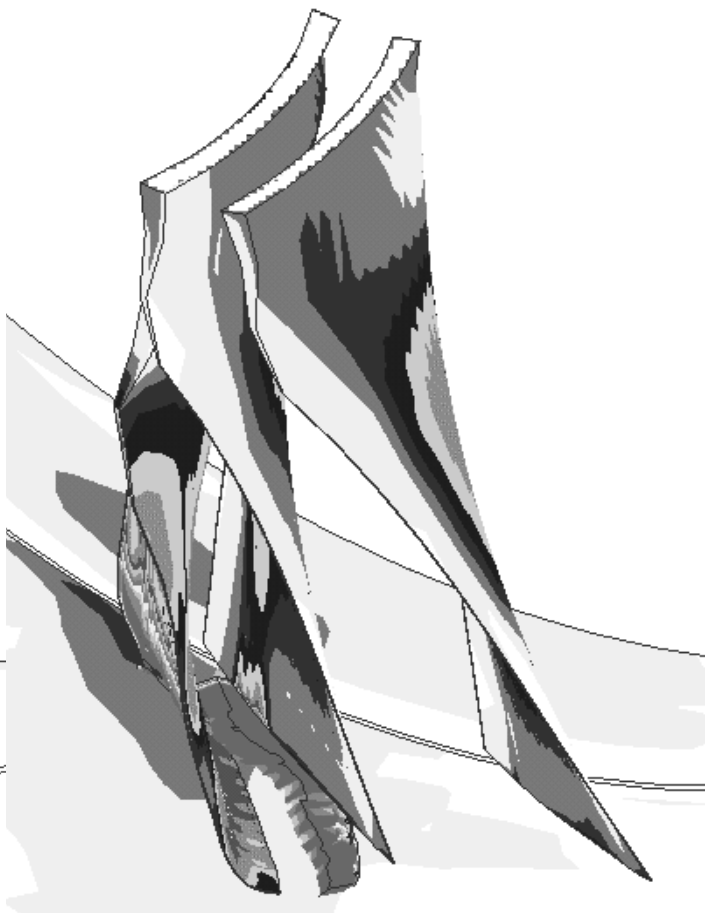

(b) Second fragment

Figure 4. Fragmentation process of the released blade 
Comparing the reconstitution of the released fan blade after the test and the position of the calculated fragments, it comes that the first fragment (figure 4) is well predicted. On the other hand, some discrepancies appear in the prediction of the other fragments, but the fragment weight proportion seems to be predicted with a sufficient accuracy. In fact, in opposition with the solid fan blades, the experimental dispersion in the FBO tests with hollow blades is significant and the correlation remains difficult.

\subsubsection{Impact on the following blade}

The behaviour of the first following blade and especially the bending under the released blade impact is essential to evaluate its capacity to withstand to the shock. Thus, the relative impact position between the two blades must be precisely simulated.

The experimental data can only be provided by the observations of the FBO film analyses and of the impact prints on the released and following blades. Consequently it makes difficult the comparison with the computation results. However, the calculated position of the impact along the chord and the height of the blade, shown in figure 5, has been compared with the experimental one: the obtained result is correct. Furthermore, as the contact between the two blades occurs after the breaking of several fragments from the released blade, and thus hinges on the fragmentation process, the good correlation suggests that this process is relatively well represented.

Modifications of the positions and instants of fragmentation change the relative impact position between the two blades indeed.

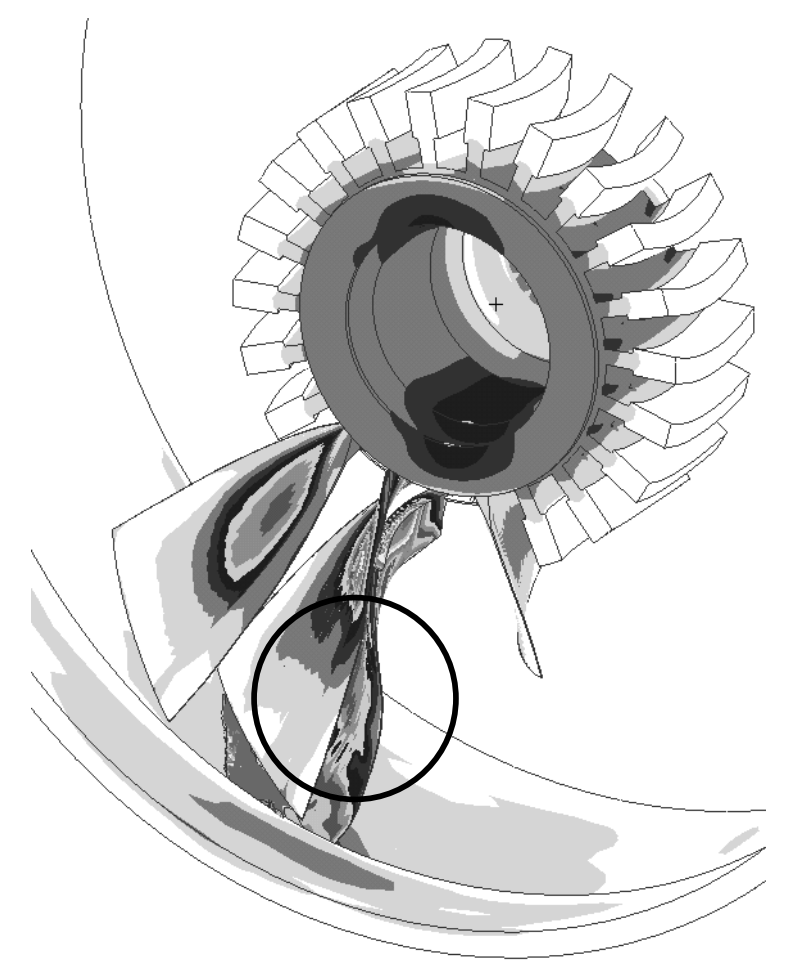

Figure 5. Impact of the released blade on the following blade 


\subsubsection{Impact on the fan casing}

The role of the fan casing is to fully contain the fragments of the released fan blade. The impact energy of the fragments has then a critical influence on the containment function of the casing. It depends on the weight and speed of the fragments, and then on the fragmentation process.

The comparison between the simulated blade impact positions on the casing and the experimental residual deformations shows good correlation. It confirms that the released blade fragments (weight and speed) are well predicted.

\subsubsection{Fuse load}

The principle of the fuse is to reduce the load in the structure to avoid the failure of very important structural components and to preserve the integrity of the aircraft. It is then supposed to break under the critical loads due to a FBO event, but not in case of light bird ingestion for instance. That is why the knowledge of its behaviour is a primary concern for the precise sizing of this specific component.

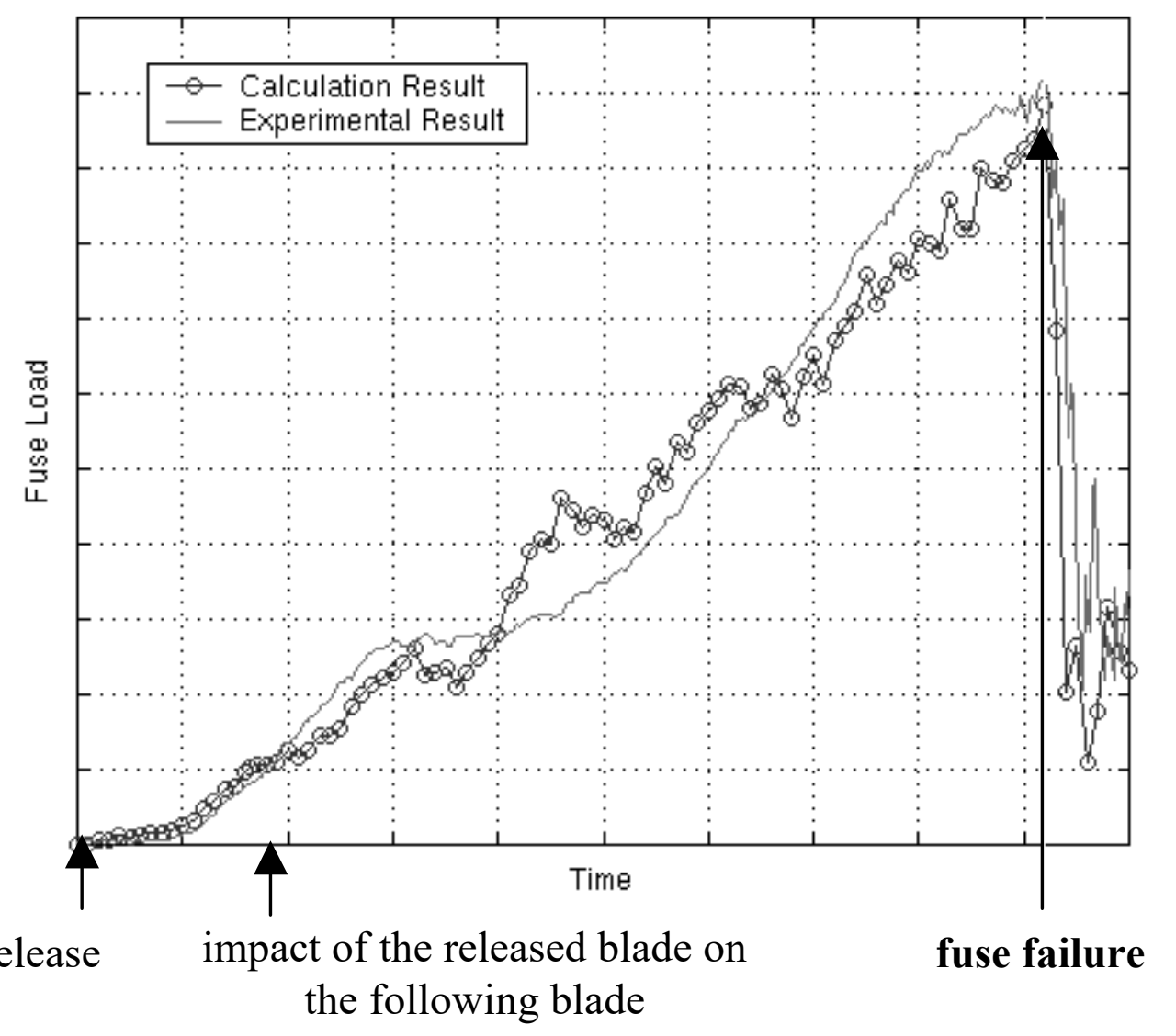

Figure 6. Fuse load versus time

By recombining the gauge signals located on strategic positions on the structure, the fuse load can be calculated. Figure 6 shows a good correlation between experiment and calculation results, considering the maximal value and the instant 
when it is reached. At this stage, the threshold value is reached, and the failure sequence of the fuse is not studied in detail but it is supposed to have completely split. The sudden fall of the load level, corresponding to the fuse failure, is in good agreement with measurements.

\subsubsection{Rotor/stator contact in the booster}

In an engine configuration, the failure of the fuse amplifies the radial displacements of the rotor and reduces the clearance between the rotor and stator. Then the low-pressure shaft hits the booster casing, avoiding the excessive orbit. This is the reason why a simplified booster had been introduced in the test rig. As shown in figure 7, the instants when the contact occurs and finishes during the first engine round are perfectly predicted. It means that the mass and stiffness of the model are correct.

On the other hand, the amplitude of the calculated contact load is about 1.5 higher than the experimental value. The physical behaviour of the test rig is thus well represented even if locally the modelisation of the contact stiffness in the booster is not very accurate. In particular, the geometry of the contact area is simplified, and the friction and local damping coefficients are not very representative. Moreover, the behaviour of the adopted flange model is too stiff.

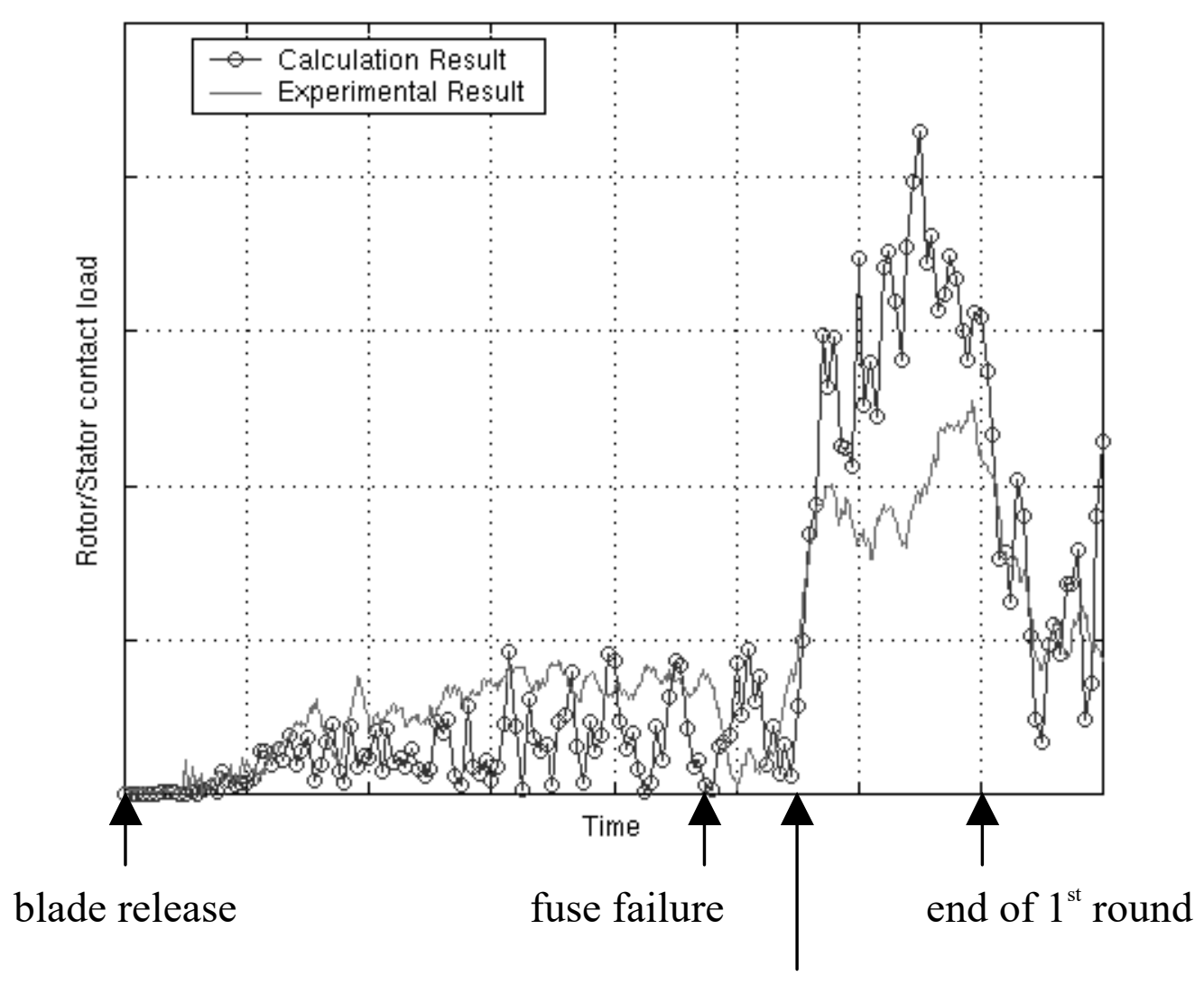

rotor/stator contact

Figure 7. Evolution of the contact load in the booster versus time 


\subsubsection{Orbit of the rotor}

The off centring of the rotor occurs as soon as the blade is released. The induced unbalanced force creates high loads in the stator, and the following blades rub against the deformed fan casing.

An important experimental datum is the largest off-centring radius of the rotor and the time when it is reached. The comparison between the test and calculation (figure 8) shows that this maximum is reached at the end of the first round after the blade loss. The only difference occurs on amplitude, the calculated displacement being $10 \%$ lower than the real one.

One of the reasons may come from the models neglecting non-linear behaviours: the bearing model, which does not take into account the plastic strains of the balls and races, and the bolted assembly model used in this application.

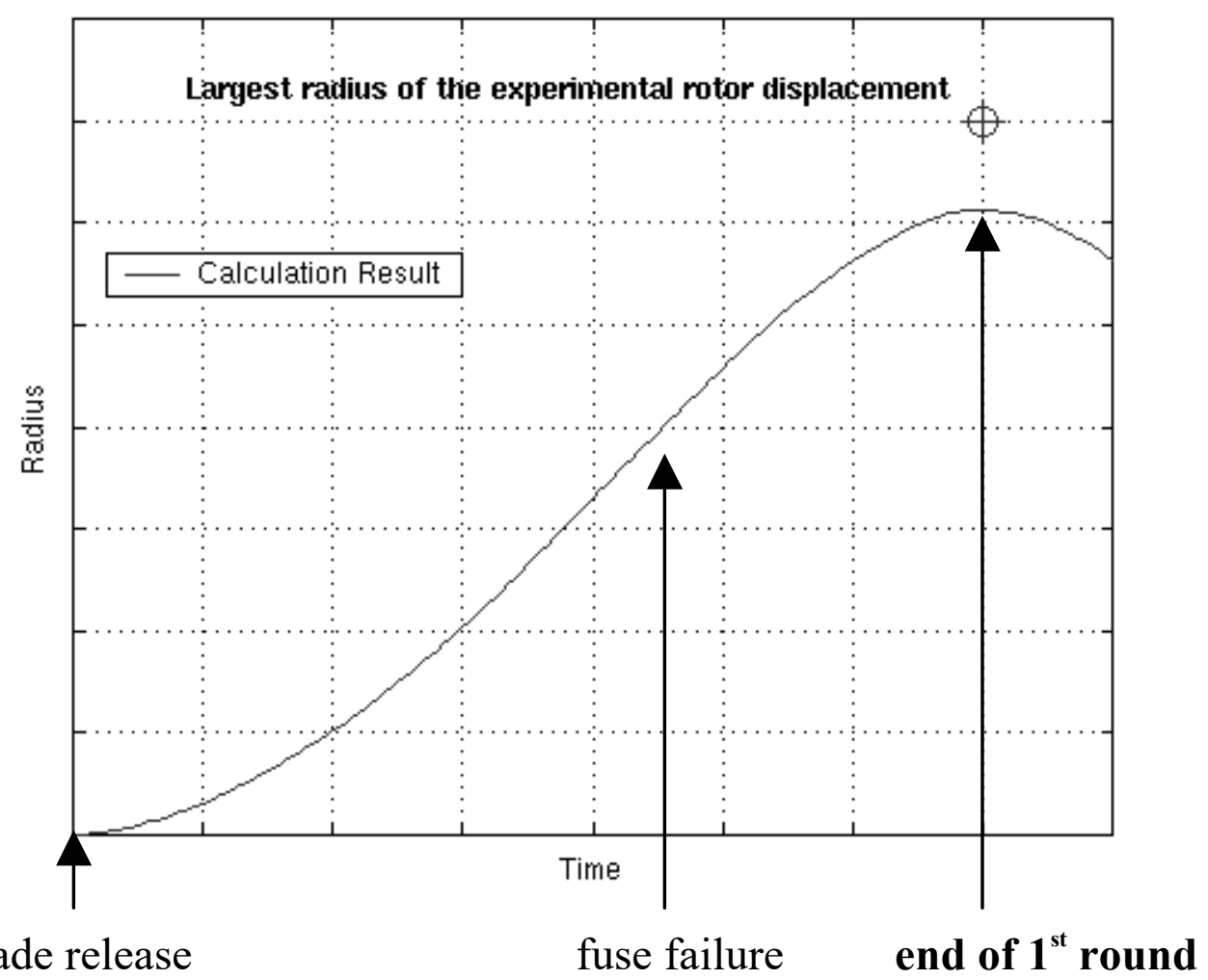

Figure 8. Evolution of the rotor off centring radius versus time

\subsubsection{Chronology - Sequence of events}

The FBO event is composed of numerous non-linear phenomena occurring successively and influencing the complete engine behaviour. Hence, it is necessary to simulate with precision each phenomenon individually. Nevertheless, the accurate reproduction of the whole chronological sequence relies on the respect of the time delay between the different events and their mutual interactions. 
The comparison of the experimental sequence of events, observed and analysed on video and gauge signals with the calculation results, shows good agreement until the end of the simulation. In particular:

- the position of the impacts of the released blade on the containment casing,

- the time interval between the first impact of the released blade on the fan casing and the impact of the released blade root on the following blade,

- the time when the main events occur and reach their maximum value: fuse load, rotor/stator contact in the booster, orbit of the rotor...

\section{Concluding remarks}

This paper has described the principles of a technique dedicated to the Fan Blade-Off transient analyses. It appeared that the complexity of the task lies in the definition of the right FE model, able to represent properly the local and global behaviour of the engine. Various and coupled types of dynamic phenomena have to be modelled indeed.

The first remark is that the analysis results concerning the sequence of events and the engine behaviour match the test results very well. Consequently the mass and stiffness of the test rig are accurately modelled. The results provide an interesting understanding of the whole engine dynamics and of the structural dynamics of its components. But they also allow a good prediction of the Fan Blade-Off event, useful for the improvement of the fan modulus and component design. However, one must consider that the prediction of the hollow blade fragments is not reached yet, and their definition still requires preliminary iterations. Some improvements would be brought by the development of new and more efficient rupture criteria.

The second remark is that the load or displacement levels are not always perfectly predicted. This is due to the simplification of non-linearity to limit the model size and CPU time. Nevertheless, CPU time still remains too long for a regular use in an industrial design process.

The improvements in future works will consist in: time,

- using different numerical techniques to considerably reduce this computation

- estimating more accurately the local dissipation in the system.

With the enhancements in some specific models and the reduction of computation time, it comes to the conclusion that the presented method is reliable for the FBO prediction. 


\section{References}

Batoz J.L., Dhatt G., Modélisation des structures par éléments finis, vol. 3, Paris, Éditions Hermes, 1992, in French.

Belytschko T., Hughes T.J.R., Computational methods for transient analysis, North Holland, 1983.

Bonini J., Bung H., "Structural impact-friction modelling in explicit finite element code with the Lagrange multiplier method", $14^{\text {th }}$ Conference on Structural Mechanics in Reactor Technology, vol. 6, p. 37-44, 1997.

Hallquist J.O., Goudreau G.L., Benson D.J., "Sliding interfaces with contact-impact in largescale Lagrangian computations", Computer Methods in Applied Mechanics and Engineering, vol. 51, p. 107-137, 1985.

Hughes T.J.R., The finite element method. Prentice Hall, 1987.

Lepareux M., Bung H., "Comportement des structures sous impact", Calcul des structures et Intelligence Artificielle, vol. 3, pp 31-52, Pluralis, 1997, in French.

Newmark M.N., "A method of computation for structural dynamics", Journal of the Engineering Mechanics Division, vol. 85, p. 67-94, 1959.

Noble J.P., Goldthorpe B.D., Church P., Harding J., "The use of the Hopkinson bar to validate constitutive relations at high rates of strain", Journal of the Mechanics and Physics of Solids, vol. 47, p. 1187-1206. 